12 Congresso Brasileiro de Inovação e Gestão

de Desenvolvimento do Produto

11 a 13 de setembro de 2019 - Universidade de Brasília UnB

\title{
REINVENTANDO E MODULARIZANDO: PENSANDO MODA INCLUSIVA PARA A TERCEIRA IDADE COM LIMITAÇÕES NOS MEMBROS SUPERIORES
}

Lívia Solino (livia.solino@ifrn.edu.br) - CST em Design de Moda / Campus Caicó / IFRN (Instituto Federal de Educação, Ciência e Tecnologia do Rio Grande do Norte)

Celina Costa (cbeatriz10@gmail.com) - CST em Design de Moda / Campus Caicó / IFRN (Instituto Federal de Educação, Ciência e Tecnologia do Rio Grande do Norte Helena Frutuoso (lenaplus@ hotmail.com) - CST em Design de Moda / Campus Caicó / IFRN (Instituto Federal de Educação, Ciência e tecnologia do Rio Grande do Norte

\section{RESUMO}

Com melhores condições de vida e os avanços na medicina, a expectativa de vida do brasileiro está cada vez maior. A fim de promover melhorias de vida para uma parcela da população que está aumentando, o presente projeto buscou desenvolver um produto de moda que atenda às necessidades do público idoso, particularmente dos que apresentam limitações nos membros superiores. Em visitas feitas à abrigos de idosos, foram realizadas entrevistas, obtendo informações mais precisas para nortear a pesquisa de maneira eficiente, e assim contribuir para o desenvolvimento de um produto que facilita o ato de vestir, ergonômico, e com maiores chances de sucesso no mercado. A pesquisa é de natureza aplicada, de caráter exploratório e utiliza uma abordagem qualitativa. Além disso, os procedimentos técnicos utilizados foram bibliográficos e de pesquisa-ação, o que possibilitou uma investigação mais profunda e subjetiva do público-alvo, permitindo a compreensão de seus comportamentos e experiências individuais, culminando em um maior conhecimento sobre o grupo analisado. Ao final do projeto, foi criada uma peça eficiente destinada aos idosos, proporcionando conforto e facilidade de uso, facilitando seu dia-a-dia.

Palavras chave: Idosos; Design ergonômico; Inovação; PDP, Moda inclusiva. 


\section{INTRODUÇÃO}

Quando analisamos os setores da cadeia produtiva de trabalho, a indústria do vestuário tem se destacado cada vez mais. O grande volume de produção de roupas e acessórios tem ajudado a movimentar a economia, pois as empresas de moda oferecem, constantemente, produtos inovadores. Tendo em vista que nas próximas décadas a população que compõe a terceira idade deve aumentar, chegando a representar 14\% da população total brasileira em 2020 (IBGE, 2011), a indústria da moda deve se preparar para o crescimento do nicho de mercado consumidor formado por idosos. Faz-se necessário, assim, que as empresas se planejem e conheçam cada vez mais as especificidades deste cliente, a fim de ampliar sua participação no mercado e consequentemente, sua lucratividade.

Apesar do aumento considerável da população idosa, a qualidade de vida que se chega a essa idade ainda deixa muito a desejar, principalmente por conta do surgimento de algumas doenças que podem acomete-los como artrose, artrite reumatoide, e bursite. Além disso, há uma grande sensibilidade ao frio, pois o sistema que regula a temperatura do corpo torna-se deficiente, interferindo na percepção desta (TREZZA, 2014). A dificuldade dos idosos de realizar movimentos dos braços, que é ocasionada por diversas doenças, transforma-se em obstáculo durante o ato de vestir-se, pois nas peças atualmente disponíveis no mercado falta flexibilidade para o uso.

Além disso, apesar dos idosos serem consumidores com poder aquisitivo, ainda não há, no mercado, produtos customizados que atendam de forma satisfatória às necessidades dessa faixa etária. As marcas se preocupam com as gerações mais novas e esquecem de um grande grupo de pessoas que também detêm o capital.

Com o cenário apresentado de uma população idosa em expansão, mas que encontra dificuldades consideráveis no ato de vestir-se de forma autônoma, surgiu a necessidade de desenvolver um produto que atendas as demandas do público alvo em questão, promovendo independência e aumento da sensação de conforto. Assim, este trabalho tem o objetivo de desenvolver um casaco que consiga proteger a pele do idoso, já que o mesmo apresenta sensibilidade a temperaturas climáticas amenas, e que o casaco apresente características que facilitem o processo do vestir, pois em muitos casos os idosos possuem limitações nos membros superiores, adquiridas no processo de envelhecimento. 
Deste modo, a pesquisa a seguir tratará sobre aspectos vivenciados pelo público da terceira idade e as particularidades sobre o universo desse consumidor. Além disso, apresentará uma análise do mercado concorrente demonstrando um panorama dos produtos ofertados para os idosos. Na sequência descreverá como o produto foi pensado e confeccionado e apontará os resultados alcançados através dos testes de usabilidades realizados em visitas aos abrigos, finalizando com as considerações finais sobre o tema e o desenvolvimento do produto.

\section{FUNDAMENTAÇÃO TEÓRICA}

\subsection{O processo de envelhecimento}

Segundo dados do IBGE (2011) o Brasil envelhece cada vez mais rápido. No ano de 2011 a população idosa era de 20,5 milhões, equivalente a $10,8 \%$ da população total. Contudo atualmente há indicativos de que em 2020 o número de idosos no Brasil passará a ser de 30,9 milhões, representando $14 \%$ da população total. Esse envelhecimento acelerado vem produzindo necessidades e demandas sociais e gerando inúmeros desafios a serem enfrentados, inclusive o da atenção aos cuidados com idosos.

Levantamentos do estudo SABE ${ }^{1}$ - Saúde, Bem-estar e Envelhecimento (2005) mostram que a população idosa, embora tenha demonstrado um aumento na expectativa de vida, no entanto apresenta uma má qualidade de vida. A pesquisa revela que muitos idosos apresentam dificuldades para desenvolver atividades básicas no seu dia a dia, como alimentar-se e tomar banho. Além disso, outros fatores, como doenças crônicas e nas articulações tornam os idosos bastante dependentes do suporte familiar ou de cuidadores.

Para Coimbra, Gasparotto e Falsarella (2014) o aumento do número de idosos já é notório e os autores propõem que haja uma atenção especial à manutenção da saúde dessa parcela da população, uma vez que passam por situações específicas, pois o processo de envelhecimento naturalmente promove modificações no corpo. É comum identificar nos idosos parâmetros de demonstram que a massa muscular foi reduzida, que a força e a densidade óssea

\footnotetext{
${ }^{1}$ http://www.scielo.br/pdf/rbepid/v8n2/05.pdf
} 
diminuíram, e que apresentam um enfraquecimento dos componentes esqueléticos, características que os deixam mais frágeis, tornando-os mais vulneráveis a quedas.

Santos et al (2009) completa que ocorrem alterações nas cartilagens, como diminuição da sua espessura, os levando a sérios problemas, principalmente quando a articulação é pouco utilizada, acontecendo assim a atrofia cartilaginosa que se apresenta em diferentes graus, e que causa a artrite. Ainda segundo o autor, a artrite, doença comum em idosos, é causadora de inflamação, dores e rigidez nos tendões, que por sua vez ocasionam bursite, tendinite e torções, resultando também em tensões ocasionadas pelo esforço excessivo ou algum movimento impróprio.

De acordo com Palacios (2004) o envelhecimento caracteriza-se pela diminuição da capacidade em condições de sobrecarga funcional, onde ocorre mudanças físicas e fisiológicas que não acontecem no mesmo grau para todos os indivíduos, variando de um organismo para outro. Pensando também sobre as particularidades dos idosos, Brito (2017) explica que com o avanço da idade, o corpo se torna mais sensível as sensações térmicas, já que o mesmo perde sua capacidade de regular a própria temperatura, acarretando aos idosos uma maior sensibilidade ao frio se comparado aos jovens.

\subsection{O mercado de moda para a terceira idade}

Vernier e Merino (2017) observam uma escassez no mercado de moda específico para a terceira idade, que contemplem suas necessidades referentes aos fatores humanos, facilitando a interação adequada entre usuários e produtos. Vianna e Quaresma (2015) observam que poucas são as pesquisas de produtos de vestuários para a população idosa. As marcas, por não apresentarem maior interesse nesses usuários, não conseguem fornecer satisfação e bem-estar ao atender seus aspectos físicos, cognitivos, sociais, organizacionais e ambientais.

Apesar do pouco interesse das empresas da indústria de moda, segundo dados do Portal do Envelhecimento (2014), os idosos têm a maior média de renda mensal do país, sendo possuidores de grande poder de compra. Assim, é importante atender as exigências de um grupo que possui poder aquisitivo e que está em processo de crescimento populacional, tornando-se um mercado preparado para atendê-los da melhor maneira. 
No Brasil atualmente não há uma marca que trabalhe com produtos específicos e pensados para as necessidades do público idoso, no entanto, grupos como Riachuelo e Renner ofertam produtos que são adquiridos por esses consumidores.

A Riachuelo possui uma imensa variedade de casacos, nas seções feminina e masculina havendo, em média 518 modelos de casaco, jaquetas e blazers. Porém não há nenhuma adaptação ou elemento inclusivo que facilite o vestir por parte do público idoso. A Renner, por sua vez, possui também uma grande variedade de casacos, jaquetas e blazers masculinos e femininos. A marca também não possui adaptação ou elemento inclusivo.

Como não foram encontradas marcas nacionais que trabalhem as especificidades do segmento de mercado da terceira idade, buscou-se encontrar marcas no exterior que apresentem esse perfil. A marca Silverts Store desenvolve artigos de vestuário para idosos com diversas limitações, como cadeirantes, idosos com incontinência urinária, entre outras doenças. A empresa atende principalmente a América do Norte, e se trata de um e-commerce.

Para as limitações apresentadas neste trabalho, a única peça que poderia atender aos idosos com limitações nos membros superiores é o cardigã (figura 1) que possui uma abertura nas costas, o que facilita a vestimenta de quem tem limitações nos membros superiores. Seu fechamento é feito através de botões de pressão com auxílio do transpasse feito no tecido das costas. O cardigã custa US\$44,62, o que corresponde em média a $\mathrm{R} \$ 168,00$ reais.

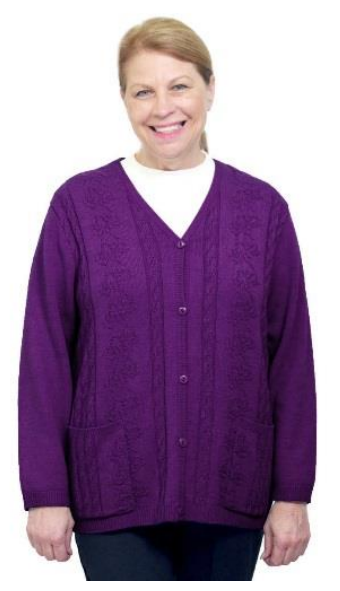

FIGURA 1 - Cardigan aberto nas costas Silvert's Store. Fonte: Disponível em:<https://www.silverts.com/show.php/product/27080-adaptive- open-backwarm-weight-cardigan-sweaterwith-pockets>. Acesso em: 14/10/2018. 
Portanto, atualmente não há, entre os concorrentes nacionais, um produto que atenda satisfatoriamente idosos que possuem limitações nos membros superiores, confirmando assim, a oportunidade de criar e introduzir no mercado, o casaco proposto.

\section{METODOLOGIA}

A natureza do trabalho foi estruturada em uma pesquisa aplicada, que segundo Fontelles et al (2009) visa a elaboração de conhecimentos científicos, trabalhando pela busca de soluções de problemas reais. Quanto a abordagem do problema, a pesquisa tem um viés qualitativo, uma vez que irá analisar profundamente as vivências dos idosos com limitações nos membros superiores (MINAYO, 2001). A metodologia para verificação do objetivo foi a de caráter exploratório que segundo Gil (2009) são feitas com o intuito de estabelecer uma visão geral do fato determinado.

Quanto aos procedimentos técnicos utilizados, o projeto iniciou com uma pesquisa bibliográfica, uma vez que foi feita a partir de materiais já elaborados, servindo de embasamento para o desenvolvimento da melhor forma de desenvolver as vestimentas propostas (GIL, 2009). Ao passo que as peças de vestuário sejam produzidas e testadas em visitas feitas no abrigo de idosos, o procedimento técnico utilizado será de uma pesquisa-ação, uma vez que está é "concebida e realizada em associação com a resolução de um problema coletivo e que os pesquisadores e os participantes representativos da situação a ser investigada estão envolvidos de modo cooperativo e participativo" (THIOLLENT, 2009).

Para que o objetivo da pesquisa fosse alcançado, 4 etapas foram adaptadas das metodologias projetuais de Löbach (2001) e Baxter (2011). Inicialmente foi feita uma fundamentação teórica, analisando a moda inclusiva, a terceira idade e a relação dos mesmo com os produtos de moda, obtendo uma maior familiaridade com o tema pesquisado. A segunda etapa abrangeu a elaboração e construção do protótipo, na terceira foram feitos testes de usabilidade com uma idosa com limitações nos braços e por fim, foi feito uma avaliação do produto e análise dos resultados alcançados. 


\section{RESULTADOS E DISCUSSÃO}

Com o passar do tempo, o idoso geralmente apresenta limitações que são ocasionadas por doenças, como por exemplo a artrite que ocasiona dificuldade na movimentação da articulação. Além das doenças, existe ainda o processo natural de envelhecimento que acaba deixando a pele mais fina e sensível, o que acarreta numa maior sensibilidade ao frio.

Frente ao exposto, foi identificada a oportunidade de desenvolver uma peça de vestuário que fosse fácil de vestir. A escolha por um casaco foi dada principalmente pela sensibilidade ao frio sentida por esse público. Para facilitar o uso, a solução encontrada foi a de confeccionar mangas transmutáveis através do uso de colchetes, uma vez que os idosos apresentam dificuldades na movimentação dos membros superiores (figura 2).

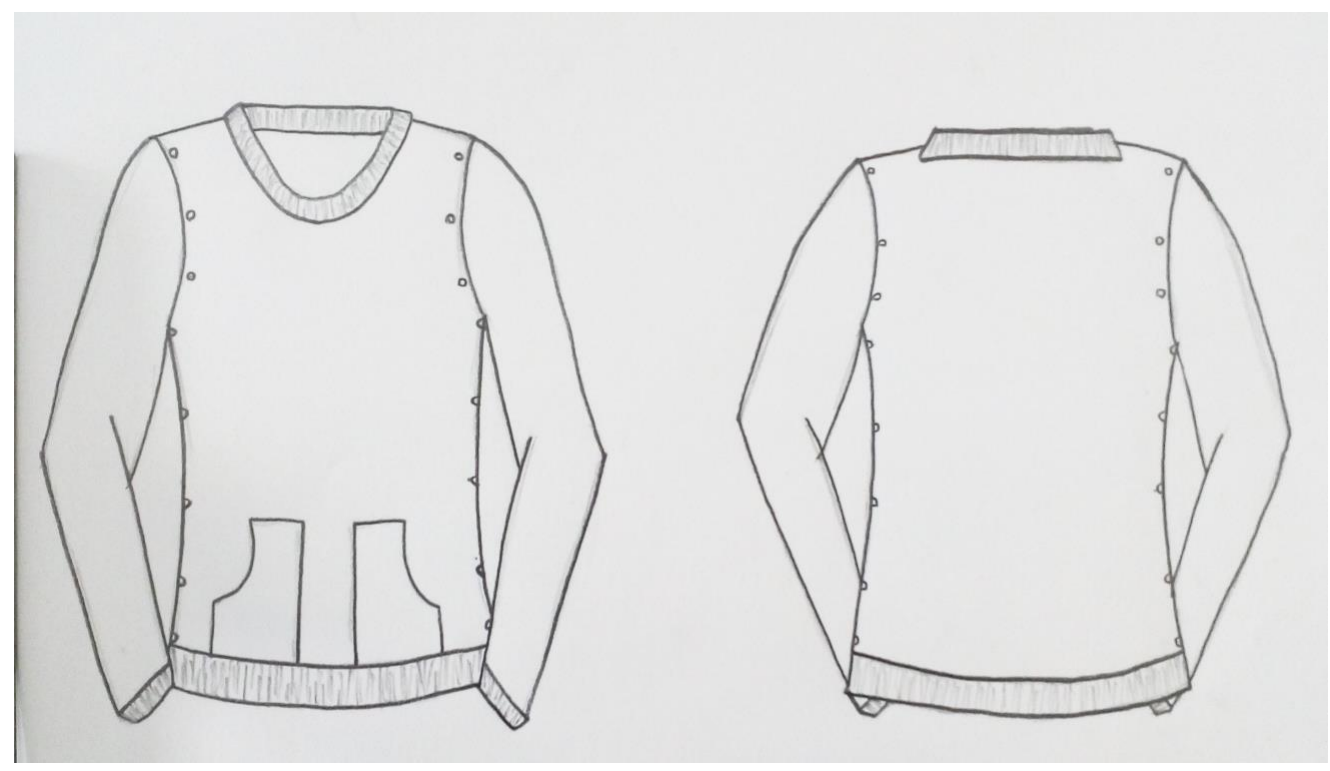

FIGURA 2 - Ideia inicial do projeto. Fonte: Acervo das autoras

Como representado na Figura 2, o produto trata-se de um casaco que possui nas duas laterais, fechamentos com utilização de botões de pressão, o que possibilita abertura total na lateral e mangas da peça, permitindo facilidade na vestimenta, sem obrigar que o idoso force a musculatura dos braços. Este casaco foi confeccionado em um tecido de flanela $100 \%$ algodão, material que é muito utilizado na fabricação de peças de bebês, por causa do seu toque suave que não agride a pele, o que também é necessário para produtos customizados para idosos.

Foi empregado também como aviamento a ribana fazendo acabamentos nas peças e o zíper. Em tecnologias que foram empregadas, foi necessário o uso de uma máquina de costura reta, uma máquina de costura de overloque, tesoura e uma mesa de corte, quanto a montagem 
da peça, foi necessário a fabricação da modelagem, corte nos tecidos conforme os moldes, costura e colocação de colchetes.

Em posse dos rascunhos, foi feita uma primeira visita a um abrigo de idosos e os croquis foram apresentados aos cuidadores que lá trabalhavam. Assim, uma modificação foi feita no produto acrescentando-se um zíper na parte frontal, pois os profissionais acreditaram que a inserção deste aviamento facilitaria o uso. Dessa forma, o primeiro protótipo elaborado foi feito acrescentando-se um zíper frontal.

Para a realização do teste de usabilidade do produto, todos os envolvidos foram convidados a participar da pesquisa como voluntários, e preencheram o Termo de Consentimento Livre Esclarecido (TCLE) autorizando a divulgação dos resultados dos testes e dos registros fotográficos em publicações de cunho científico.

Após ser confeccionado o primeiro protótipo, foi realizada uma segunda visita em um abrigo de idosos, onde ocorreu o teste de usabilidade (figura 3). Uma vez que, de acordo com Baxter (2011), é de suma importância ser feito um teste que comprove a eficácia do produto. A figura 3 demonstra a vestimenta em uma idosa que possui mínima mobilidade nos membros superiores, fazendo com que o fato da peça ter as mangas transmutáveis facilitasse o processo de vestir. Ficou evidenciado ainda a facilidade que os colchetes agregaram ao casaco, o que também promoveu mobilidade quanto ao processo do vestir.

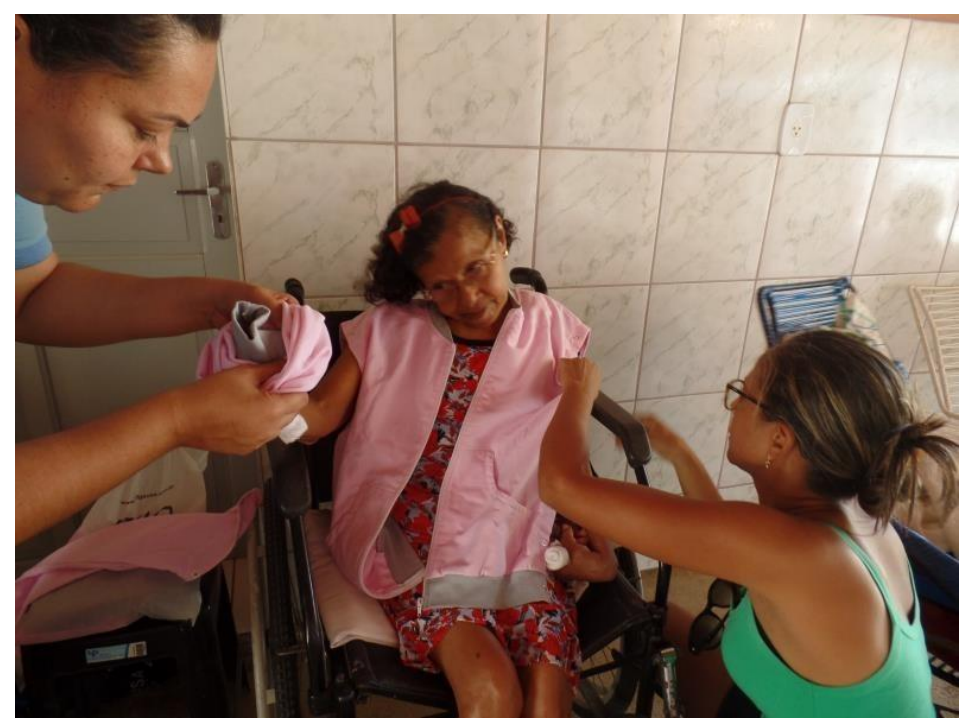

FIGURA 3 - Teste de usabilidade. Fonte: Acervo das autoras (2019). 
Quando indagado aos cuidadores de idosos do abrigo, quais impressões tiveram sobre o protótipo, os mesmos relataram que gostaram e avaliaram de maneira positiva. Eles ressaltaram que os botões de pressão agregaram facilidade ao ato de vestir. Com a realização do teste de usabilidade foi possível confirmar a eficiência do casaco, pois a vestimenta da peça se deu num tempo de 3 minutos, comprovando a sua facilidade de uso.

\section{CONSIDERAÇÕES FINAIS}

Para a execução satisfatória do trabalho, foi feito uma revisão da literatura sobre o universo dos idosos e constatou-se que os mesmos passam por muitas mudanças físicas, que tem que ser levadas em conta quando se pensa na criação de peças destinadas a esse público. $\mathrm{Na}$ sequência procurou-se identificar as marcas que atendessem esse mercado e percebeu-se que o público não é atendido de forma satisfatória.

Por esses motivos, surgiu a necessidade de criar um casaco que supra as necessidades do idoso. Assim desenvolveu-se um produto com um material que apresenta toque macio e que não prejudica a pele do idoso. Além disso a peça tem mangas transmutáveis, que facilitam o vestir do idoso. Tudo isso colaborando para que esse público obtenha um produto que melhor atenda às suas necessidades.

É importante frisar que a idosa escolhida para o teste de usabilidade, vive em uma situação extrema, pois tem uma grande limitação na movimentação de seus braços, concluído que, se a peça foi eficiente para ela, que tem mobilidade quase zero, servirá de forma satisfatória para outros idosos em situações menos graves.

Por fim, o objetivo do trabalho foi alcançado ao receber feedback positivo durante o teste de usabilidade, desenvolvendo um vestuário inovador e que proporciona conforto térmico e facilidade no uso, além de apresentar uma boa flexibilidade e se mostrando eficiente no ato de vestir, promovendo a inclusão de pessoas com deficiências nos membros superiores, acarretando melhorias a vida do idoso. Os elementos estéticos, como cor e forma também foram bem aceitos pelo público. Com a construção dessa peça foi compreendido que é possível inovar pensando nas particularidades de um público alvo ainda pouco visualizado pela indústria da moda. 
Este projeto contribui para a discussão sobre moda inclusiva, principalmente relacionada à terceira idade, ao apresentar relatos sobre a relação dos usuários com o produto desenvolvido. A intenção é gerar discussões a respeito do assunto, contribuindo não apenas para o meio acadêmico, mas também na vida social dos envolvidos.

\section{REFERÊNCIAS}

BRITO, Paula. O calor e o nosso bem-estar. 2017. Disponível em:<http://www.cparoquial- covapiedade.pt/calorbem-estar/>. Acesso em: 24 de novembro de 2018.

COIMBRA, Arlete Maria Valente; GASPAROTTO, Lívia Pimenta Renó; FALSARELLA, Gláucia Regina - As quedas no cenário da velhice: conceitos básicos e atualidades da pesquisa em saúde.Rev. Bras. Geriatr. Gerontol. Rio de Janeiro, 2014. Disponível em:<www.scielo.br/reeusp>. Acesso em 09 de setembro de 2018.

FONTELLES, M. J. et al. Metodologia da pesquisa científica: diretrizes para elaboração de um protocolo de pesquisa. <file:///C:/Users/VAGNER/Desktop/PROJETO\%20DE\%20EXTENSÃO/falando\%20sobre\%20pesquisa.pdf>. Acesso em: 18 de março de 2019.

GIL, Antonio Carlos. Estudo de caso. Atlas, 2009.

GIL, Antonio Carlos. Métodos e técnicas de pesquisa social. São Paulo, 2009.

INSTITUTO BRASILEIRO DE GEOGRAFIA E ESTATÍSTICA - IBGE. Estaísticas sociais. Rio de janeiro, 2018. Disponível em: <https://agenciadenoticias.ibge.gov.br/agencia-noticias/2012-agencia-denoticias/noticias/20980-numero-de-idosos-cresce-18-em-5-anos-e-ultrapassa-30-milhoes-em-2017>. Acesso em: 18 de março de 2019.

INSTITUTO BRASILEIRO DE GEOGRAFIA E ESTATÍSTICA - IBGE. Sinopse do Senso Demográfico de 2010. Rio de Janeiro, 2011.

LAKATOS, E. Maria; MARCONI, Marina. de Andrade. Fundamentos de metodologia científica: Técnicas de pesquisa, v. 7, 2010.

LEBRÃO, Maria Lúcia; LAURENTI, Rui. Saúde, bem-estar e envelhecimento: o estudo SABE no Município de São Paulo. Revista brasileira de epidemiologia, v. 8, p. 127-141, 2005.

MINAYO, M. C. Pesquisa social. Teoria, método e criatividade. $18^{\circ}$ ed. Petrópoles: Vozes, 2001.

PALACIOS, J. Mudanças e desenvolvimento durante a idade adulta e velhice. 2004. Disponível em:< https://www.passeidireto.com/arquivo/28103629/palaciosidadeeinflunciasnodesenvolvimento_20170306125324pdf>. Acesso em: 28 de abril de 2019.

PORTAL DO ENVELHECIMENTO. O poder de compra numa nova terceira idade. Disponível em: $<$ https://www.portaldoenvelhecimento.com.br/o-poder-de-compra-numa-nova-terceira-idade/>.Acesso em: $17 \mathrm{de}$ março de 2019.

RIBEIRO, Eduardo. Interação social e envelhecimento ativo: um estudo em duas praças de Natal/RN. Tese (Doutorado em Psicologia) - Universidade Federal do Rio Grande do Norte. Natal, 2014.

SANTOS, Claudia Batitucci dos, SENNA Plínio Mendes, LUCENA, Juliana Maria Silvia Carneiro de, BARBOSA, Célia Marisa Rizzatti. Relação entre o envelhecimento, problemas articulares e disfunção temporomandibular - Revista Brasileira de Pesquisa em Saúde, 2009; 11(1): 46-51

THIOLLENT, Michel. Pesquisa-ação nas organizações. Atlas, 2009.

TREZZA, Beatriz Maria. O efeito da exposição ao calor sobre o desempenho cognitivo de idosos: um estudo controlado. 2014. Tese de Doutorado. Universidade de São Paulo.

VARNIER, Thiago; MERINO, Eugenio Andrés Díaz. Fatores humanos aplicados a produtos de moda: materiais têxteis com termorregulação voltados ao público idoso - HFD, v.6, n.11, p 72- 
VIANNA, Claudia; QUARESMA, Manuela. ERGONOMIA: CONFORTO TÊXTIL NO VESTUÁRIO DO IDOSO - $15^{\circ}$ ERGODESIGN- Congresso Internacional de Ergonomia e Usabilidade de Interfaces HumanoTecnologia: Produto, Informações, Ambientes Construídos e Transportes; USIHC - Congresso Internacional de Ergonomia e Usabilidade de Interfaces Humano-Computador - ConferencePaper · June 2015. Disponível em: < www.scielo.br/reeusp>. Acesso em 09 de setembro de 2018. 